\title{
A AUTONOMIA PROFISSIONAL COMO ESTRATÉGIA DE MOTIVAÇÃO
}

\section{ARTIGO DE REVISÃO}

JUCÁ, Layane Aguiar da Silva Oliveira ${ }^{1}$

JUCÁ, Layane Aguiar Da Silva Oliveira. A autonomia profissional como estratégia de motivação. Revista Científica Multidisciplinar Núcleo do Conhecimento. Ano 06, Ed. 07, Vol. 12, pp. 66-73. Julho de 2021. ISSN: 2448-0959, Link de acesso: https://www.nucleodoconhecimento.com.br/administracao/estrategia-de-motivacao, DOI: $\quad 10.32749 /$ nucleodoconhecimento.com.br/administracao/estrategia-demotivacao

\section{RESUMO}

Como um direito de todos, a comunicação e o estudo têm sido ótimos aliados no que diz respeito ao senso crítico de cada cidadão. Um ser "pensante" e com capacidade de se expor devidamente mostra ao mundo seus ideais, competências e dificuldades demonstrando a si mesmo do que é capaz. Atualmente muitas pessoas têm conhecimento de que é preciso bastante esforço para aprender de maneira autônoma, e ser assim um profissional engajado concluindo seus objetivos com sabedoria e bom senso, seguro de si e fazendo o suficiente para ter eficiência em seu trabalho, ajudando da melhor maneira possível, a fim de conquistar um futuro promissor. Este trabalho tem a finalidade de apresentar benefícios de um profissional com autonomia para assim lidar com as adversidades do cotidiano, feito a partir de pesquisas bibliográficas. Seus objetivos são entender a autonomia; compreender quem são os oprimidos na falta de autonomia para assim mudar seus posicionamentos como apenas ouvintes e recebedores de tarefas; observar motivos

\footnotetext{
${ }^{1}$ Pós-graduada Lato Sensu em nível de especialização, na área de educação, em pedagogia empresarial e educação corporativa - faculdade de educação São Luís.
}

RC: 92494

Disponível em: https://www.nucleodoconhecimento.com.br/administracao/estrategia- 
que levam esses funcionários a serem reclusos ou a utilizarem seus poderes de decisão em situações necessárias/solicitadas. E como objetivo geral estimular a capacidade de autonomia em profissionais que trabalham em empresas. Como conclusão observaremos o fato de que um profissional seguro torna seu trabalho mais eficiente.

Palavras-chave: Autonomia, Profissional, Empresa, Comunicação.

\section{INTRODUÇÃO}

As pessoas conhecem suas limitações ao se comunicarem e se expressarem no ambiente de trabalho. Algumas vezes a timidez toma conta do organismo dessa pessoa ocasionando o fato de nenhuma palavra fluir. O medo de falar em público existe e afeta boa parte da população de acordo com Osório (2008). É a chamada "glossofobia", definida pelo dicionário Aurélio como medo anormal de falar em público. É no momento desse medo que outro colega de trabalho mais seguro de si "passa na frente" e se comunica com os superiores e pode ser melhor notado devido sua comunicação.

Os objetivos desse trabalho são: entender a autonomia; compreender quem são os oprimidos na falta de autonomia para assim mudar seus posicionamentos como apenas ouvintes e recebedores de tarefas; observar motivos que levam esses funcionários de grandes empresas a serem reclusos ou a utilizarem seus poderes de decisão em situações necessárias/solicitadas. E como objetivo geral estimular a capacidade de autonomia de profissionais que trabalham em empresas.

O trabalho em questão justifica-se na necessidade de demonstrar em empresas, que cada componente é necessário e deve saber agir em várias situações.

RC: 92494

Disponível em: https://www.nucleodoconhecimento.com.br/administracao/estrategia- 


\section{DESENVOLVIMENTO: A AUTONOMIA EM SUA FORMA DE SER}

A palavra "autonomia" de acordo com o dicionário Aurélio significa direito ao livrearbítrio que faz com que qualquer indivíduo esteja apto para tomar suas próprias decisões. Para Kant, é uma faculdade do ser humano de se autogovernar de acordo com seus padrões de conduta moral sem que haja influência de outros aspectos exteriores.

A autonomia é um termo que traz contradições. Algumas pessoas dizem que a autonomia pode chegar ao egocentrismo, ao querer fazer tudo sozinho, sendo assim independente. Mas a autonomia torna a pessoa mais liberta e segura de si, um cidadão que busca aprender e escutar o que o outro tem a dizer/oferecer, para a partir daí organizar seus pensamentos e chegar a uma conclusão. A autonomia deve ser respeitada, como o pensador Paulo Freire (1996) mostra a seguir.

O respeito à autonomia e à dignidade de cada um é um imperativo ético e não um favor que podemos ou não conceder uns aos outros. Precisamente porque éticos podemos desrespeitar a rigorosidade da ética e resvalar para a sua negação, por isso é imprescindível deixar claro que a possibilidade do desvio ético não pode receber outra designação senão a de transgressão. (FREIRE, 1996, p. 25)

Como uma realidade a ser respeitada, a autonomia é um direito de cada pessoa e não deve ser restrita. É uma busca por conhecimento de si mesmo e ação perante os outros.

É comum ao analisar uma situação com a qual não se concorda, ficar observando, porém com vários pensamentos e ainda assim nada fazer. Mas e se isso acontecesse no ambiente de trabalho e sem uma autoridade maior presente na empresa? Certamente dependeria que certo profissional avaliasse com os demais para assim tomar uma atitude sensata. Infelizmente não é o que acontece em todos os casos.

RC: 92494

Disponível em: https://www.nucleodoconhecimento.com.br/administracao/estrategia- 
Muitas pessoas têm uma "trava" emocional que os impossibilita de agir em momentos de tensão por se sentirem pressionadas. Alguns perdem a voz, preferem não opinar até que o superior chegue e dê sua decisão; outros escutam o que um colega tem a dizer e simplesmente aceitam, causando assim um ciclo de hierarquia em que somente quem possui os maiores cargos pode tomar alguma decisão sem colaboração dos demais, independente da situação.

O funcionário sem atitude causa desconforto ao cliente e certas vezes à equipe. Isso faz com que ele receba o título de oprimido. Como diz Freire (1987).

Quem, melhor que os oprimidos, se encontrará preparado para entender o significado terrível de uma sociedade opressora? Quem sentirá, melhor que eles, os efeitos da opressão? Quem, mais que eles, para ir compreendendo a necessidade da libertação? Libertação a que não chegarão pelo acaso, mas pela práxis de sua busca; pelo conhecimento e reconhecimento da necessidade de lutar por ela. Luta que, pela finalidade que the derem os oprimidos, será um ato de amor, com o qual se oporão ao desamor contido na violência dos opressores, até mesmo quando esta se revista da falsa generosidade referida. (FREIRE, 1987 p. 17)

Um cidadão que procurou aprender o necessário para seu trabalho, que estudou para isso, e que também conhece a cultura organizacional da empresa, sabe ouvir e respeitar opiniões alheias. Sim, esse cidadão também merece expor seu conhecimento, sua opinião, tomar partido de uma situação quando necessário e permitido, colaborando dessa forma em seu ambiente de trabalho e ficando bem consigo mesmo naquela sensação de dever cumprido.

Esse profissional consegue demonstrar suas capacidades em benefício do próximo, solucionando um problema imediato na empresa em que trabalha, ou adiando uma preocupação que não precisa ser resolvida naquele momento. Ele acaba se destacando de uma forma boa, como funcionário que observou, alertou, conversou, ouviu, e assim ganhou a confiança dos demais presentes. Esse profissional se destaca por ter características de um bom líder, de uma pessoa com autonomia.

RC: 92494

Disponível em: https://www.nucleodoconhecimento.com.br/administracao/estrategia- 
Segundo Idalberto Chiavenato (1999):

Podemos definir liderança como a uma influência interpessoal exercida numa situação dirigida através do processo de comunicação humana com objetivos específicos. Os elementos que caracterizam a liderança são, portanto, quatro: a influência, a situação, o processo de comunicação e os objetivos a alcançar. (CHIAVENATO, 1999, p. 558)

Dessa forma é mais fácil não se sentir menosprezado ou oprimido pela maioria, fazendo a diferença e demonstrando-se importante.

Assim, podemos dizer que, para Kant, a autonomia é a vontade própria. É governar-se por si mesmo. É a escolha racional e emocional. E a escolha que não leva em conta as conseqüências externas e imediatas dos atos e nem as regras, por pura prudência, inclinação, interesse ou conformidade. (CHRISTINO, 1997, p. 73)

Sobre as questões emocionais e racionais, é necessário agir com cautela e sensatez a cada tomada de decisão para não infringir objetivos da empresa. E lembrar-se sempre de que não está sozinho, mas agindo também por outras pessoas para um bem comum da organização, exercendo a liderança.

Assim como diz Gonçalvez (2007),

Agir com autonomia exige visão de interdependência entre os diversos profissionais com quem trabalha; respeito ao próximo; reconhecimento de seus próprios limites; lealdade na competição; atitude de arcar com as conseqüências de suas ações, positivas ou não; e autocrítica permanente. (GONÇALVEZ, 2007).

E na vida? Fora do ambiente de trabalho? A pessoa que tem autonomia e organiza ações para concluir seus objetivos muitas das vezes tem melhor desempenho e satisfação em comparação àquela pessoa que somente guarda pensamentos e cumpre ordens sem sequer pensar ou questionar.

$\mathrm{Na}$ vida seria da mesma forma. A pessoa que está bem consigo expõe melhor seu pensamento, demonstra sua forma de agir, e produz atos que podem transformar

RC: 92494

Disponível em: https://www.nucleodoconhecimento.com.br/administracao/estrategia- 
seu cotidiano ou seu futuro para melhor. Esse é o fato, a segurança, pois é ela que traz a autonomia.

Segundo Freire (1996):

Há um sinal dos tempos, entre outros, que me assusta: a insistência com que, em nome da democracia, da liberdade e da eficácia, se vem asfixiando a própria liberdade e, por extensão, a criatividade e o gosto da aventura do espírito. A liberdade de mover-nos, de arriscarnos vem sendo submetida a uma certa padronização de fórmulas, de maneiras de ser, em relação às quais somos avaliados. É claro que já não se trata de asfixia truculentamente realizada pelo rei despótico sobre seus súditos, pelo senhor feudal sobre seus vassalos, pelo colonizador sobre os colonizados, pelo dono da fábrica sobre seus operários, pelo Estado autoritário sobre os cidadãos, mas pelo poder invisível da domesticação alienante que alcança a eficiência extraordinária no que venho chamando "burocratização da mente". (FREIRE, 1996, p.43)

O ser crítico e reflexivo ajuda quando possível, seja no ambiente de trabalho, com amigos ou outro lugar. O ser autônomo já não é mais considerado oprimido, pois ele anseia por mudanças e melhorias, e não deixa o mundo lhe "massacrar" com egoísmos, egocentrismos e opressão.

A autonomia também engloba a comunicação que é necessária no ambiente de trabalho. O funcionário que consegue comunicar-se bem e passar suas informações e pensamentos adiante quando necessário, melhora o ciclo de qualidade de vida e convivência no trabalho, melhorando também a si mesmo.

Já no sentido oposto, o funcionário que não tem autonomia e comunicação acaba gerando a desmotivação no ambiente de trabalho.

RC: 92494

Disponível em: https://www.nucleodoconhecimento.com.br/administracao/estrategia- 
Figura 1. Ponto RH: Desmotivação do trabalho, o que fazer?

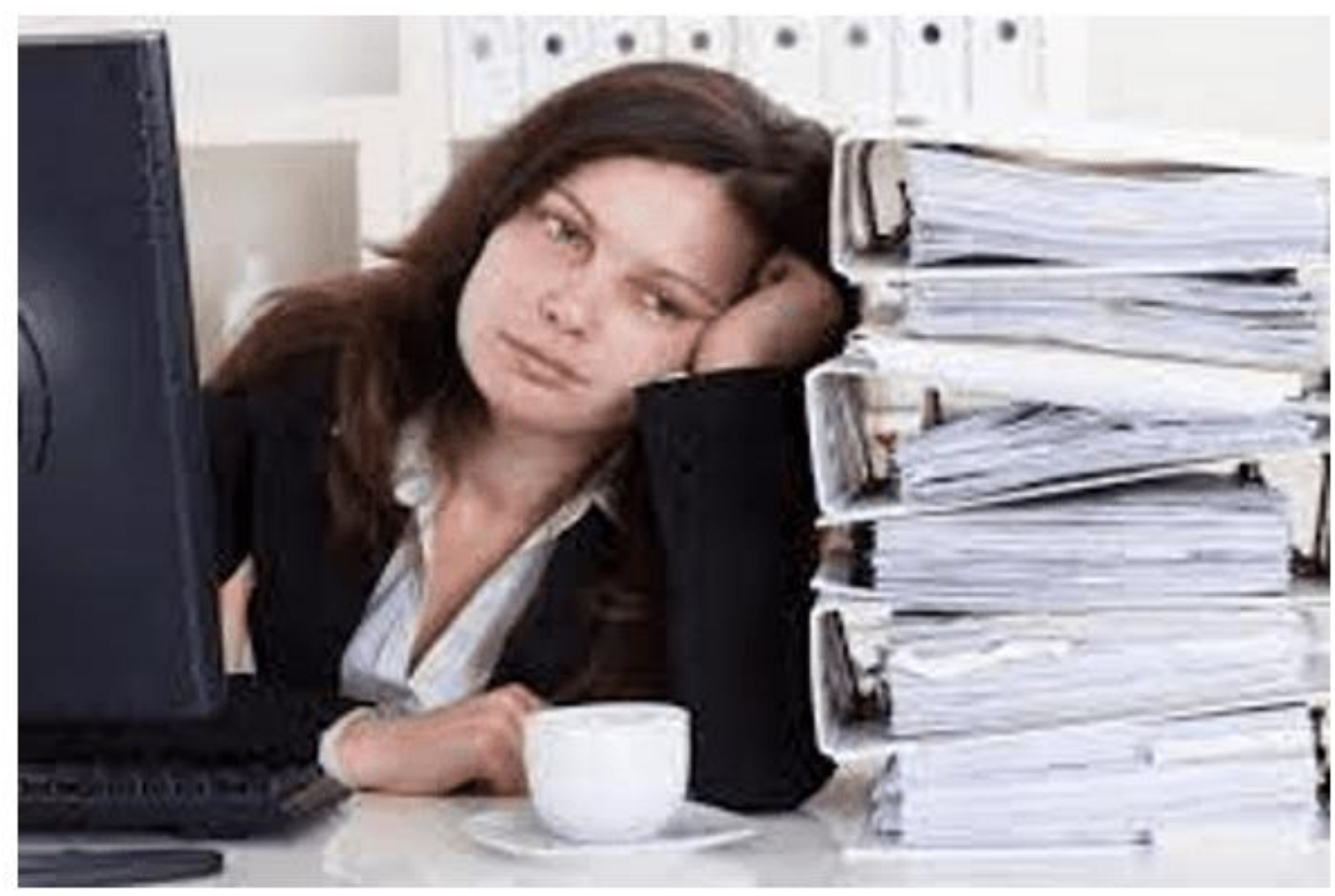

Fonte: Disponível em: <https://www.pontorh.com.br/desmotivacao-trabalho-fazer/>. Acesso em 10 jun. 2021.

A autonomia ajuda a pessoa a conviver melhor no ambiente de trabalho, dar sua opinião, mesmo que seja necessário pedir orientação. Assim vai se desenvolvendo, conquistando seu lugar no mundo e sentindo toda importância que possa ter. É importante não "passar por cima" de ninguém, sempre respeitar a todos manter uma boa comunicação, eficiência e comprometimento.

\section{CONSIDERAÇÕES FINAIS}

Ter autonomia na vida é muito importante, pois faz enxergar as coisas de outra maneira, ter conhecimentos, elevar níveis, aprender mais. A pessoa também acaba

RC: 92494

Disponível em: https://www.nucleodoconhecimento.com.br/administracao/estrategia- 
se conhecendo mais e melhorando suas funções e aptidões. Torna-se mais crítica sobre assuntos, melhor comunicativa e se faz entender perante os outros.

As pessoas têm muito mais a oferecer do que geralmente aparentam. Elas precisam de motivação, oportunidade, ajuda de um profissional, incentivo em seu próprio ambiente de trabalho e foco. Existem muitos talentos desperdiçados que ficam guardados somente no inconsciente de cada ser por falta de autonomia.

O trabalho em questão mostrou que o ser humano é capaz de fugir do estereótipo de "oprimido" e assumir as rédeas de suas ações, se aperfeiçoando. Certamente não é algo fácil, pois a tomada de decisão, o ato de falar em público, e a coragem são estímulos que precisam ser trabalhados algumas vezes com ajuda de profissionais, mas não é algo impossível. Com o esforço necessário cada pessoa conseguirá perder um pouco da timidez, expor suas opiniões e levar eficiência em seu local de trabalho. Tendo autonomia os objetivos fluem melhor e a qualidade de vida também.

\section{REFERÊNCIAS}

CHIAVENATO, Idalberto. Gerenciando Pessoas - 3 ${ }^{a}$ Ed. São Paulo: Makron Books, 1994.

CHRISTINO, Raquel Rosan.Piaget e Kant: Uma comparação do conceito de autonomia. Nuances, Vol. III, 1997. Disponível em: http://revista.fct.unesp.br/index.php/Nuances/article/viewFile/60/61. Acesso em: 10 abr. 2019.

COELHO, André. Ponto RH: Desmotivação do trabalho, o que fazer? Disponível em: https://www.pontorh.com.br/desmotivacao-trabalho-fazer/. Acesso em 10 jun. 2021.

RC: 92494

Disponível em: https://www.nucleodoconhecimento.com.br/administracao/estrategia- 
Dicionário Aurélio 2. Disponível em: https: //www.dicio.com.br/Aurélio-2/. Acesso em: 10 jun. 2021.

FREIRE, Paulo. Pedagogia da Autonomia. Pedagogia da autonomia: saberes necessários à prática educativa. 25a edição. São Paulo, Paz e Terra, 1996. Disponível em http://forumeja.org.br/files/Autonomia.pdf. Acesso em: 27 mar. 2019.

FREIRE, Paulo. Pedagogia do Oprimido. $17^{\text {a }}$ edição. Rio de Janeiro, Paz e Terra, 1987.

http://www.dhnet.org.br/direitos/militantes/paulofreire/paulo_freire_pedagogia_do_op rimido.pdf. Acesso em: 22 mar. 2019.

GONÇALVES, Isabella. A importância da autonomia. Gestão de Negócios, Recursos Humanos. 464 ${ }^{a}$ edição. 2007. Disponível em: http://www1.redegestao.com.br/cms/opencms/desafio21/artigos/gestao/rh/0014.html. Acesso em: 21 mar. 2019.

LAWLER, E. Motivação nas organizações de trabalho. In: BERGAMINI, C., CODA; R. (Org.). Psicodinâmica da vida organizacional - Motivação e liderança. 2. ed. São Paulo: Atlas, 1997

NASSAR, Paulo. Comunicação Interna - A força das empresas. Aberje Editorial, São Paulo, 2003.

Enviado: Abril, 2021.

Aprovado: Julho, 2021.

RC: 92494

Disponível em: https://www.nucleodoconhecimento.com.br/administracao/estrategia- 